\title{
Quantifying Antimicrobial Use in Dutch Companion Animals
}

\section{OPEN ACCESS}

Edited by:

Carolee Anne Carson,

Public Health Agency of Canada

(PHAC), Canada

Reviewed by:

Cedric Muentener,

University of Zurich, Switzerland

Roswitha Merle,

Freie Universität Berlin, Germany

*Correspondence:

Ingeborg M. van Geijlswijk

I.M.vanGeijlswijk@uu.nl

Specialty section:

This article was submitted to

Veterinary Epidemiology and

Economics,

a section of the journa

Frontiers in Veterinary Science

Received: 25 February 2019

Accepted: 08 May 2019

Published: 28 May 2019

Citation:

Hopman NEM, van Dijk MAM,

Broens EM, Wagenaar JA,

Heederik DJJ and van Geijlswijk IM (2019) Quantifying Antimicrobial Use

in Dutch Companion Animals.

Front. Vet. Sci. 6:158.

doi: 10.3389/fvets.2019.00158

\begin{abstract}
Nonke E. M. Hopman ${ }^{1}$, Marloes A. M. van Dijk ${ }^{1}$, Els M. Broens ${ }^{1}$, Jaap A. Wagenaar ${ }^{1,2,3}$, Dick J. J. Heederik ${ }^{2,4}$ and Ingeborg M. van Geijlswijk ${ }^{2,5 *}$
\end{abstract}

1 Department of Infectious Diseases and Immunology, Faculty of Veterinary Medicine, Utrecht University, Utrecht, Netherlands, ${ }^{2}$ The Netherlands Veterinary Medicines Institute (SDa), Utrecht, Netherlands, ${ }^{3}$ Wageningen Bioveterinary Research, Lelystad, Netherlands, ${ }^{4}$ Division Environmental Epidemiology, Institute for Risk Assessment Sciences, Utrecht University, Utrecht, Netherlands, ${ }^{5}$ Pharmacy Department, Faculty of Veterinary Medicine, Utrecht University, Utrecht, Netherlands

Antimicrobial resistance (AMR) is an increasing threat, both in human and in veterinary medicine. To reduce the selection and spread of AMR, antimicrobial use (AMU) should be optimized, also in companion animals. To be able to optimize AMU, a feasible method to quantify AMU and information on current AMU are needed. Therefore, a method to quantify AMU was developed, using the number of Defined Daily Doses Animal (DDDA). This method was used to explore applied antimicrobial classes and to identify differences in prescribing patterns in time and between veterinary clinics. Antimicrobial procurement data of the years 2012-2014 were collected retrospectively from 100 Dutch veterinary clinics providing care for companion animals. The mean number of DDDAs per clinic per year decreased significantly from 2012 to 2014. A shift in used classes of antimicrobials (AMs) was seen as well, with a significant decrease in use of third choice AMs (i.e., fluoroquinolones and third generation cephalosporins). Large differences in total AMU were seen between clinics ranging from 64-fold in 2012 to 20-fold in 2014. Despite the relative low and decreasing AMU in Dutch companion animal clinics during the study, the substantial differences in antimicrobial prescribing practices between clinics suggest that there is still room for quantitative and qualitative optimization of AMU.

Keywords: antimicrobial, antibiotic, companion animals, veterinary medicine, defined daily dose, DDDA, prescribing

\section{INTRODUCTION}

Antimicrobial resistance (AMR) is an increasing threat, both in human and in veterinary medicine. Many antimicrobials (AMs) used in veterinary medicine are used in human medicine as well. Due to the close contact between people and their companion animals, the importance of companion animals as potential reservoirs of (multi)-resistant pathogens for humans has received increasing attention (1-5). Besides the potential public health threat, AMR also has a direct impact on animal health and welfare, because of treatment failure. To prevent selection and spread of resistant bacteria and to keep AMs valuable for the future, antimicrobial use (AMU) should be optimized.

From 2008 onwards, AMU in Dutch food producing animals received increasing attention, actions were taken at different levels and AMU was reduced considerably (6-9). Most actions addressed food producing animals, but classification of AMs in 1st, 2nd, and 3rd choice AMs [Werkgroep Veterinair Antibiotica Beleid (Working Party for Policy on Veterinary 
Antimicrobials) $]^{1}$ and legislation on mandatory susceptibility testing for the use of 3rd choice AMs (10) also hold for companion animals.

Risk management of AMR needs to be based on valid and most updated information. Therefore, it is crucial to monitor the amount and types of AMs used in animals. Amounts and types of AMs used in animals have been investigated in several countries, particularly in food producing animals (11-16). Only a few studies describe AMU and prescribing patterns in companion animals (17-21). The majority of studies regarding AMU in companion animals uses total sales or prescription data expressed in kilograms of AMs (18), the mass of active AM substances (by AM class or subclass) in relation to a specified population to express AMU or the number of prescriptions $(15,20-22)$. These different measurement units make it hard to compare data between these studies. The European Medicines Agency, European Surveillance of Veterinary Antimicrobial Consumption group (EMA ESVAC) has introduced the veterinary Defined Daily Doses for Animals $\left(D_{\text {VET }}\right)$ to objectify the numerator $(23,24)$. DDDVET is defined as a "technical unit of measurement similar to the Defined Daily Dose (DDD), usually based on recommendations from the Summary of Product Characteristics (SPC) and in some cases based on scientific literature, intended for the purpose of drug consumption studies. $\mathrm{DDD}_{\mathrm{VET}}$ is assigned per kilogram animal per species per day" $(23,24)$. According to ESVAC, objective AMU data collection should also be organized for companion animals, rabbit production and aquaculture (25).

The aim of present study was to quantify systemic AMU in Dutch companion animal clinics (2012-2014) using Defined Daily Doses Animal (DDDA) established according to the Dutch authorization of the veterinary medicinal products, to explore applied antimicrobial classes and to identify differences in prescribing patterns in time and between veterinary clinics.

\section{MATERIALS AND METHODS Study Design and Data Collection}

A retrospective survey was performed. The Royal Dutch Veterinary Association (KNMvD) provided contact details of all 1,149 veterinary clinics in the Netherlands which treated companion animals. All these clinics were invited by mail to participate, followed by a reminder after 2 weeks by e-mail. Requested data were clinic population data and antimicrobial veterinary medicinal product (AVMP) procurement data for the subsequent years 2012, 2013, and 2014. Mixed-animal clinics with combined, unspecified procurement data for companion animals and non-companion animals were excluded from the study, because products with a multi-species (companion and food producing animal) registration could not be allocated to specific animal species.

${ }^{1}$ WVAB-richtlijn classificatie van veterinaire antimicrobiële middelen. Available: https://www.wvab.nl/

\section{Calculation of DDDAs}

In the Netherlands, AMs for veterinary use are on prescription only and sold to companion animal owners (or farmers) by veterinarians exclusively. Therefore, antimicrobial procurement data are supposed to reflect the total amount of AMs used in animals. These procurement data were used to calculate

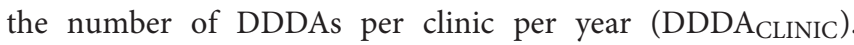
For each year and clinic, the number of ordered packages of AVMPs for systemic use was provided, identified by their unique European Article Number (EAN)-code. To calculate the number of DDDAs per clinic, two variables are needed (13). First, the total animal mass in kilogram that can be treated for 1 day with the amount of AMs prescribed; for every individual AVMP this can be derived from the "DG-standaard" by EANcode. The DG-standaard is an online Dutch database containing all packages of AVMPs once authorized in the Netherlands, managed by the Netherlands Veterinary Medicines Institute. For every single AVMP package, per species the total animal mass in kilogram that can be treated is defined, preferably based on authorized doses, for cascade use based on comparable AVMPs or literature [SDa (the Netherlands Veterinary Medicines Institute) $]^{2}$. This database was initially developed and applied for the monitoring of antimicrobial consumption in the major food producing animal sectors, enabling e.g., benchmarking of farms within sectors. Second, the total weight (in $\mathrm{kg}$ ) of the clinic animal population at risk to be treated with the AVMP. The latter was estimated based on the clinic animal population represented by the number of dogs, cats and rabbits attending the clinic at least once in a specified 3-year period. The total weight was calculated by multiplying the number of dogs, cats and rabbits with previously established average body weights for dogs $(19.1 \mathrm{~kg})$ and cats $(4.1 \mathrm{~kg})(26)$, for rabbits the average weight was based upon expert opinion $(2.5 \mathrm{~kg})$. For every AVMP, the denominator was determined separately depending on the animal species the AVMP was authorized for. By dividing the two variables for all individual AVMPs and consequently adding up the outcomes, the total number of DDDAs is obtained. This sum of all AVMPs is suitable for comparison between clinics and between consecutive years (DDDA CLINIC). .

This calculation results in the indicator $\mathrm{DDDA}_{\mathrm{CLINIC} / \text { year }}$ that represents the theoretical number of days per year an average animal (dog, cat or rabbit) was treated with AVMPs

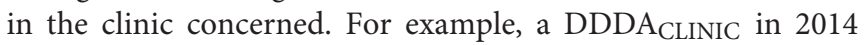
of 2 implies that the average dog, cat and rabbit in care of this veterinary clinic has received 2 days of AM-treatment in 2014.

\section{Classification of AMU}

Classification of AMU in present study (Table 1) is according to the Dutch policy on veterinary AMU [Werkgroep Veterinair Antibiotica Beleid (Working Party for Policy on Veterinary Antimicrobials)] ${ }^{1}$.

${ }^{2}$ DG-standaard (Dutch database for AVMPs). Available: https://cdn.i-pulse. $\mathrm{nl} /$ autoriteitdiergeneesmiddelen/userfiles/Publicaties/sda-standard-operatingprocedure-dg-standaard-januari-2015.pdf 
TABLE 1 | Classification of veterinary antimicrobials (AMs) in 1st, 2nd, and 3rd choice AMs, according to Dutch policy on veterinary AMU.

\begin{tabular}{|c|c|c|}
\hline Classification & Reasoning & Main classes of AMs \\
\hline 1st choice & $\begin{array}{l}\text { Empirical therapy; do not } \\
\text { select for (to current } \\
\text { knowledge), nor are specifically } \\
\text { meant for treatment of } \\
\text { ESBL-producing } \\
\text { micro-organisms }\end{array}$ & $\begin{array}{l}\text { Tetracyclines, } \\
\text { nitroimidazoles, } \\
\text { narrow-spectrum penicillins, } \\
\text { trimethoprim, sulfonamides, } \\
\text { and phenicols }\end{array}$ \\
\hline 2nd choice & $\begin{array}{l}\text { All AMs not classified as 1st or } \\
\text { 3rd choice AMs; Use of these } \\
\text { AMs might select for } \\
\text { ESBL-producing bacteria or is } \\
\text { specifically indicated in case of } \\
\text { an ESBL-infection }\end{array}$ & $\begin{array}{l}\text { Aminopenicillins } \\
\text { (with/without } \\
\text { beta-lactamase inhibitors), } \\
\text { 1st generation } \\
\text { cephalosporins, } \\
\text { aminoglycosides and } \\
\text { colistin }\end{array}$ \\
\hline 3rd choice & $\begin{array}{l}\text { Highest priority critically } \\
\text { important AMs for human } \\
\text { medicine according to WHO; } \\
\text { By Dutch law restricted to use } \\
\text { only in individual animals and } \\
\text { after culture and susceptibility } \\
\text { testing }\end{array}$ & $\begin{array}{l}\text { Fluoroquinolones, 3rd and } \\
\text { 4th generation } \\
\text { cephalosporins }\end{array}$ \\
\hline
\end{tabular}

\section{Statistical Analysis}

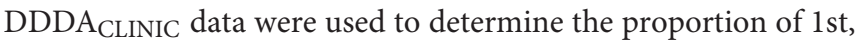
2nd, and 3rd choice AMs, to identify trends in AMU during the study period and to identify differences between clinics. Mixed models were used to explore the variation in AMU over time, both within and between clinics. Models for AMU (total, 1st, 2nd, and 3rd choice) were fitted using PROC GLIMMIX (SAS 9.4, SAS Institute, Inc., Cary, NC, USA) assuming a lognormal distribution and allowed for changes in residual variance over time. Within clinic correlations were modeled using an autoregressive $[\mathrm{ARH}(1)]$ model and a random intercept. The year of prescription was included as a categorical covariate and statistical significance was tested for using likelihood ratiotesting, comparing model fit to that of a model that not included this covariate (both fitted using maximum likelihood). $P<0.05$ were considered statistically significant.

\section{RESULTS}

\section{Inclusion of Clinics}

In total, 155 veterinary clinics responded and were willing to provide specified antimicrobial procurement data $(13.5 \%$ of the total number of invited clinics). Because of missing data or Practice Management System (PMS) incapability to properly report the animal population data, 44 clinics were excluded. Procurement data from 111 veterinary clinics (period 20122014) were included and analyzed. Data from $11 / 111$ veterinary clinics turned out to be inconsistent or unrealistic, i.e., reporting an unexpectedly high or low number of dogs or cats (about 10times higher or lower than the average clinic) or AVMPs for food producing animals appeared to be incorrectly ascribed to companion animals. Therefore, results are based on data of 100 participating clinics.

\section{Antimicrobial Use: Changes Over Time and Differences Between Clinics}

The mean number of DDDAs per clinic per year (DDDA CLINIC $_{\text {) }}$ decreased from $2.33( \pm 1.46)$ in 2012 to $1.88( \pm 1.20)$ in 2014 (Figure 1). Use of 2nd choice AMs also decreased during the study period $[0.97( \pm 0.77)$ in 2012 to $0.81( \pm 0.63)$ in $2014]$ as was the case for 3rd choice AMs $[0.55( \pm 0.38)$ in 2012 to $0.14( \pm 0.15)$ in 2014] (Figure 2). First choice AMU increased from $0.81( \pm 0.93)$ in 2012 to $0.93( \pm 0.71)$ in 2014. Mixed model analyses of AMU (log-transformed data) indicated that all differences between 2012 and 2014 were statistically significant.

In 2012 and 2013, 2nd choice AMs were the most frequently used compounds ( 42 and $46 \%$ of total AMU), whereas in 2014, 1 st choice AMs were most frequently used (50\% of total AMU). With regard to the groups of AMs used, aminopenicillins (with or without clavulanic acid) defined as 2nd choice AMs, represented the largest group in all three consecutive years (2012; 31\%, $2013 ; 36 \%$ and $2014 ; 36 \%$ of total AMU). In 2012, the second largest group of AMs consisted of 3rd generation cephalosporins (i.e., cefovecin) (14\% of total AMU), in 2013 and 2014 the second largest group consisted of trimethoprim/sulfonamides (11 and 13\% of total AMU, respectively) which are 1st choice AMs. The use of fluoroquinolones and 3rd generation cephalosporins (both 3rd choice AMs) decreased from a mean

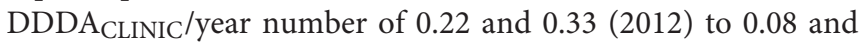
0.07 (2014), respectively.

The majority of systemically used AMs were orally administered (2012 66\%; 2013 73\%; 2014 77\%, respectively). However, major part of 3rd choice AMs were applied parenterally (2012 67\%; 2013 63\%; 2014 55\%, respectively), although this distribution is shifting toward more oral use as well.

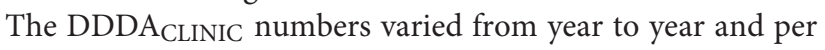
clinic (Figures 3, 4). From 2012 to 2014, overall DDDACLINIC numbers from individual clinics ranged from 0.11 (minimum DDDA $_{\text {CLINIC, }} 2013$ ) to 7.5 (maximum DDDACLINIC, 2014). In 2012, the between clinic difference in total AMU was almost 64-fold (Figure 3). In 2014, the between clinic difference was smallest and amounted a 20 -fold difference between the minimum and maximum DDDA ${ }_{\text {CLINIC }}(0.37-7.50)$ (Figure 4). An interesting detail in this observation is that a higher minimum

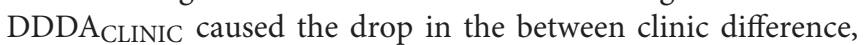

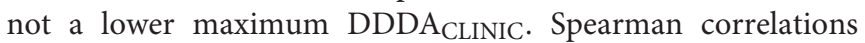
between repeated measures of total AMU for different pairs of years ranged between 0.7 and 0.8 . Regarding the use of 3rd choice AMs, the between clinic difference was larger. Five clinics reported no 3rd choice AMU in 2014. The lowest use that was reported accounted for a DDDA $A_{\text {CLINIC }}$ of 0.001 while the maximum use was 0.70 in the same year, accounting for a 500-fold difference in 3rd choice AMU between clinics in 2014.

Statistical modeling established the observed differences in AMU between clinics by the mixed model analyses of AMU (log-transformed data) with a heterogeneous AR(1) model, a random "clinic" effect and year of prescription as a covariate. For total AMU the residual variances decreased by $26 \%$ from 2012 to 2014. However, for 3rd choice AMU the residual variances 


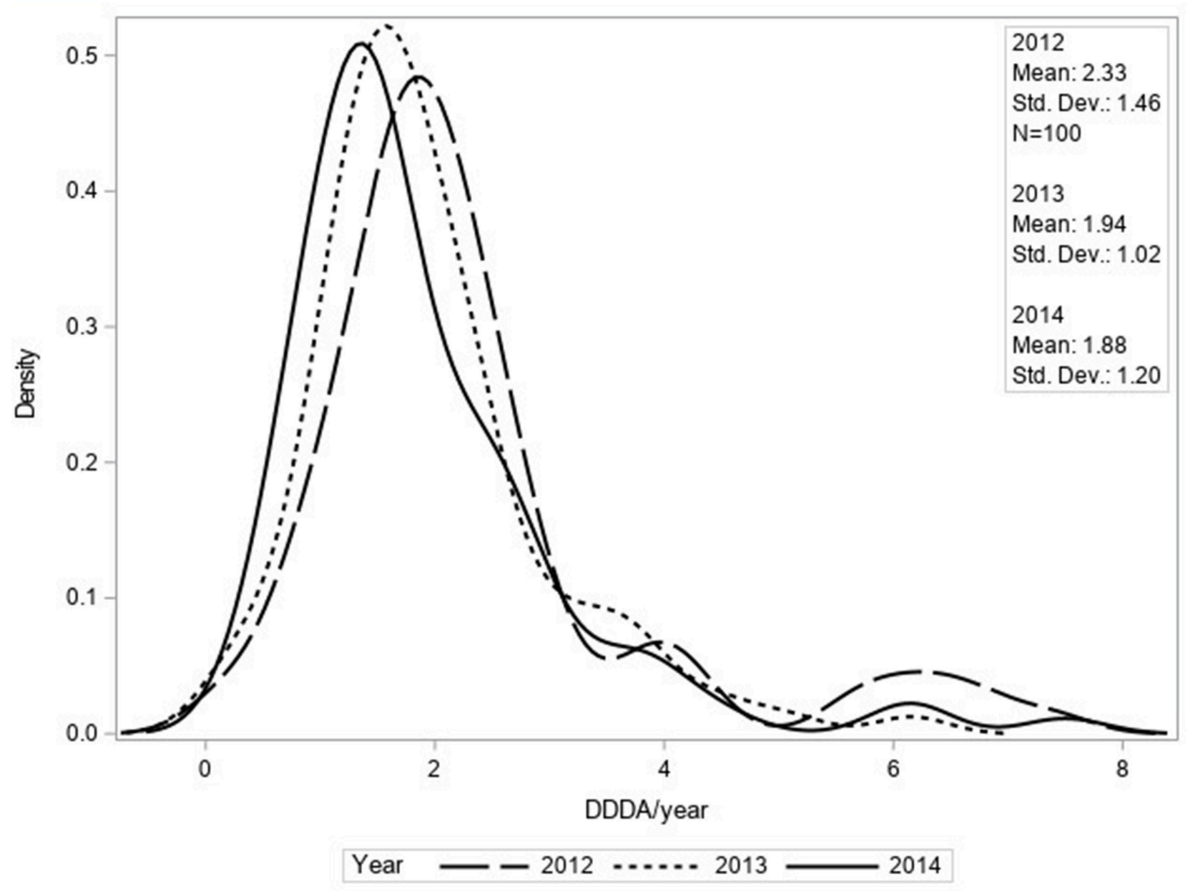

FIGURE 1 | Density function of DDDACLINIC/year for total AMU based upon procurement data of 100 clinics for 2012,2013, and 2014.

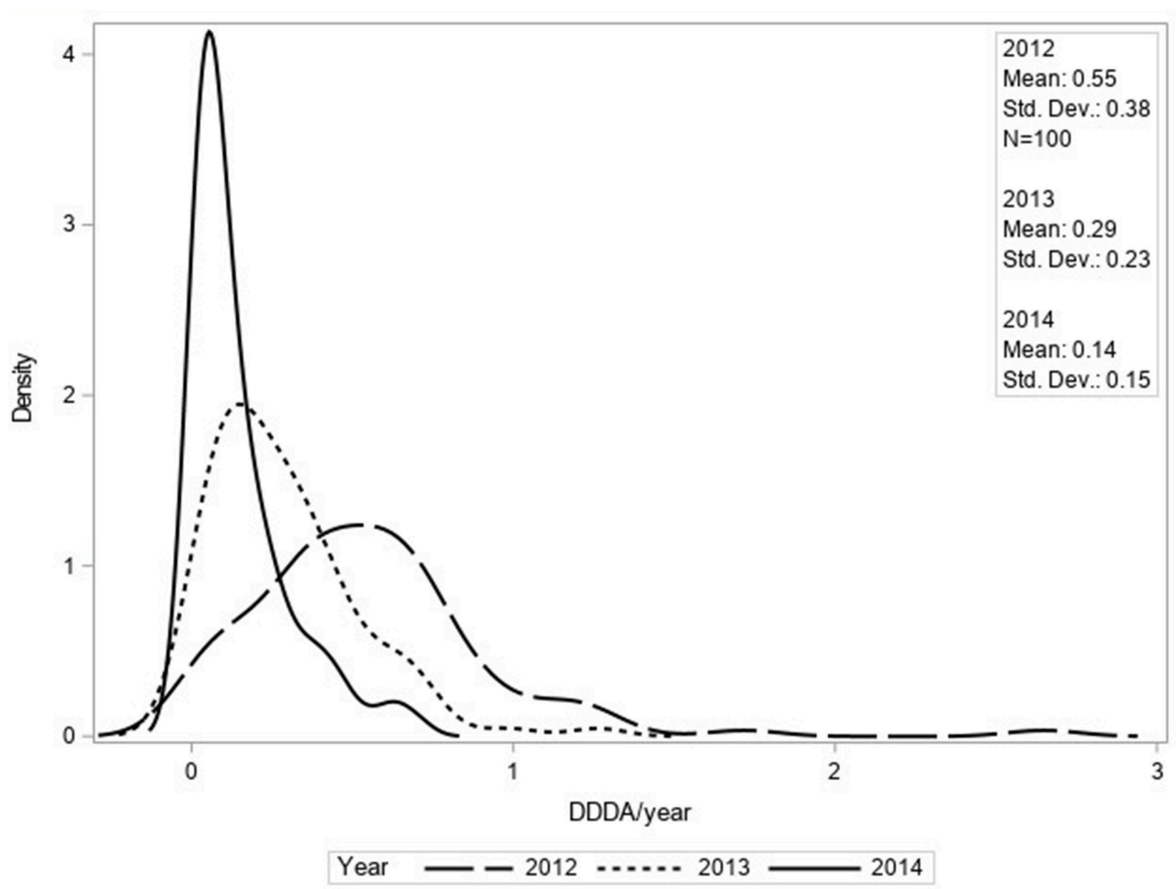

FIGURE 2 | Density function of DDDACLINIC/year for third choice AMU based upon procurement data of 100 clinics for 2012,2013 , and 2014. 


\section{DDDA $_{\text {CLINIC }} 2012$}

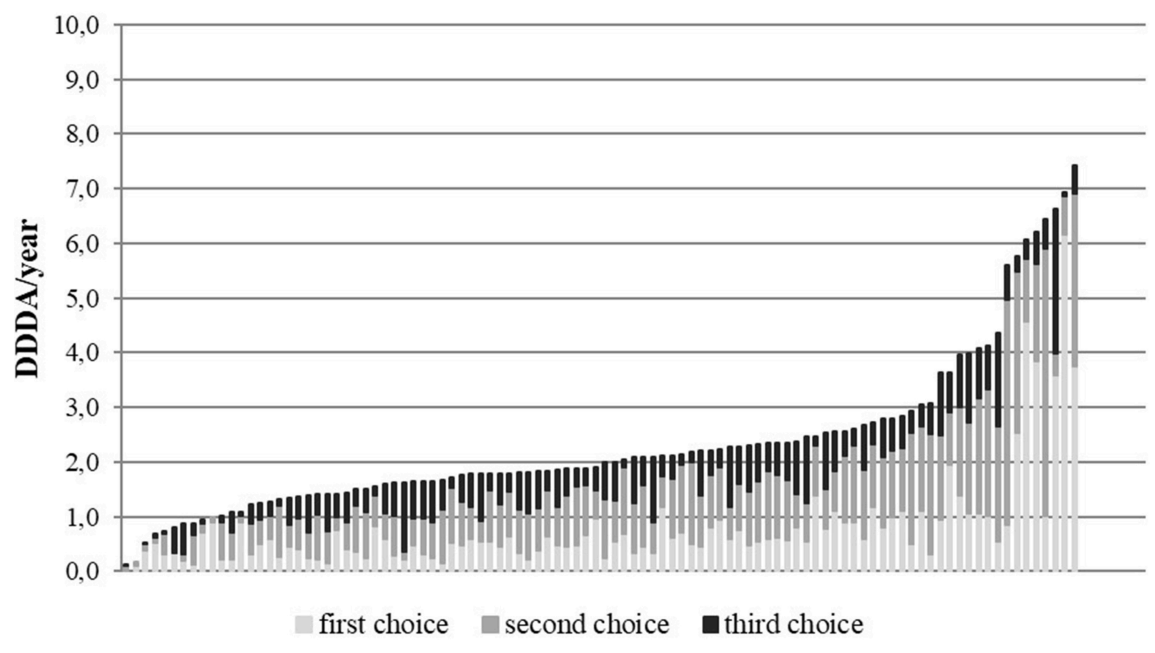

FIGURE 3 | DDDACLINIC figures for all 100 clinics in 2012, specified for first, second, and third choice antimicrobials, showing the differences in AMU between clinics (based upon procurement data of these 100 clinics).

increased by $102 \%$, indicating that differences between clinics for the use of these AMs became more prominent over time. The estimated correlation between residuals of repeated measures of total AMU for a single clinic for different pairs of years ranged from 0.62 to 0.77 (using log-transformed data), indicating that clear systematic differences exist between practices in AMU.

\section{DISCUSSION}

The present study used the number of DDDAs per clinic to express AMU in companion animals. By applying DDDAs dosing differences between AMs due to e.g., the relative potency and differences in pharmacokinetics, are taken into account, as well as dosing differences between species. This measure enables objectified comparison over time and between clinics, even internationally. This measure is adopted in monitoring AMU in food producing animals and endorsed by EMA ESVAC (23). Despite the advantages of a more harmonized way of presenting AMU, there are some disadvantages as well. Disadvantages of using DDDAs are linked to the way DDDAs are calculated. Two variables are needed for this calculation (13) (1) a numerator expressing the total treated animal weight and (2) a denominator expressing the total weight of the clinic animal population. Both variables might be biased. For the numerator this might be the case when an AVMP is authorized for use in more than one animal species. The majority of AVMPs in this study is authorized for more than one of the companion animal species concerned and due to lacking prescription information, it could not be specified whether these AVMPs were prescribed to dogs, cats, and/or rabbits. When it is unknown whether the product has been administered to dogs, cats, or rabbits, the resulting

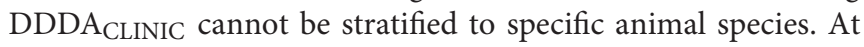

the same time, to be able to determine the total treated animal weight in case of an AVMP that is authorized for more than one companion animal species, the numerator was calculated using the average number of kilograms treated of the species the AVMP was registered for. As an example, if an AVMP was authorized for both dogs, cats and rabbits, the average number of treated kilograms of dogs, cats, and rabbits was calculated as the numerator. In food producing animals, prescription data are collected on farm level making it easier to allocate the AVMPs to specified animal species. Only prescription data (identifying the animal the AVMP was prescribed for) can mitigate this problem of AVMPs authorized for more than one companion animal species. For the denominator, bias might be caused by the total weight of the different animal species and the clinic animal population represented by the number of dogs, cats, and rabbits attending the clinic at least once in a specified 3year period. In our study, the total clinic animal population of all 100 participating clinics consisted of 228,000 dogs, 228,000 cats, and 25,000 rabbits. These 100 clinics represented $8.7 \%$ of 1,149 veterinary clinics treating companion animals in the Netherlands. When these numbers are extrapolated and compared to official estimates on the number of dogs, cats and rabbits in the Netherlands (27), the total number of dogs in the Netherlands is overestimated (correction factor 0.57), the number of cats seems to be estimated correctly (correction factor 0.99 ) and the number of rabbits is underestimated (correction factor 4.13). The discrepancies between the number of dogs and rabbits registered in veterinary clinics vs. official estimates in the Netherlands (based upon a survey among 7,500 Dutch households) might be explained by the fact that rabbit owners consult a veterinarian less often and dog owners might visit more different clinics (e.g., for a second opinion). The relatively high number of dogs compared to rabbits, might also be explained by 


\section{DDDA $_{\text {CLINIC }} 2014$}

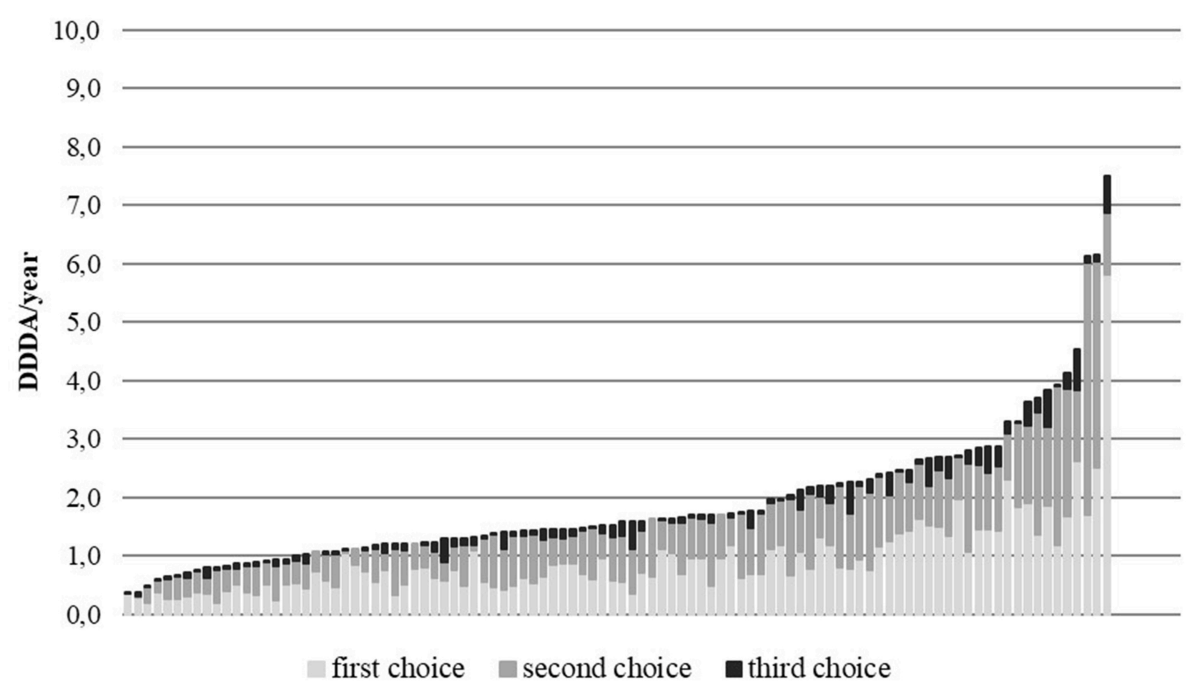

FIGURE 4 | DDDACLINIC figures for all 100 clinics in 2014, specified for first, second, and third choice antimicrobials, showing the differences in AMU between clinics (based upon procurement data of these 100 clinics).

the fact that rabbit owners mainly visit a veterinarian in case a rabbit is ill, while dog and cat owners might also seek preventive veterinary medicine (e.g., yearly check-ups, vaccinations etc.).

Additional calculations taking above mentioned correction factors into account, result in a mean overall AMU of 2.8 DDDA/year in 2012 (vs. 2.33 without correction factors), 2.34 DDDA/year in 2013 (vs. 1.94 without correction factors), and 2.27 DDDA/year in 2014 (vs. 1.88 without correction factors). Third choice AMU accounted for a mean DDDA/year of 0.69 in 2012 (vs. 0.55), 0.36 in 2013 (vs. 0.29), and 0.19 in 2014

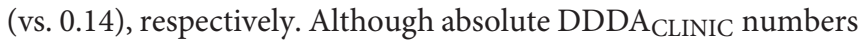
are higher using the correction factors, observed trends and patterns in AMU and differences between clinics remain the same. Regarding the applied denominator per clinic, the absolute

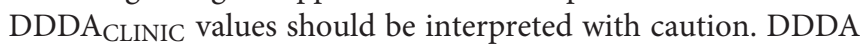
is a powerful and objective measure. For comparisons over time and between studies, the denominator should be well-defined.

This study shows a significant decrease of AMU from a

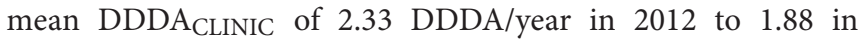
2014. This decrease was combined with a clear shift in classes of AMs used. Increased attention for AMU in general and national action plans to establish reduction of AMU in food producing animal sectors, appeared to have affected AMU in Dutch companion animals as well. Not only in the Netherlands, but also in other countries a recent decrease in AM prescriptions in companion animals was reported $(20,21)$. However, in present study considerable differences in AMU between clinics were seen, suggesting possibilities for optimization of AMU. Given the observation that repeated measures of total AMU from one specific clinic were clearly correlated and substantial betweenclinic differences were observed, it would be worth focusing on those clinics with less favorable figures first, although differences between clinics reduced with decreasing use as well. Because $3 \mathrm{rd}$ choice AMU was already relatively low, yearly use tended to fluctuate more. Therefore, repeated measures of 3rd choice AMU from one specific clinic appeared less correlated.

Despite a significant reduction in total AMU and especially in 3rd choice AMs [CIAs of highest priority for human medicine according to WHO (28)], the use of these AMs still accounted for $7.7 \%$ of total AMU in 2014. However, hard to compare due to using different measurements of AMU, other countries report similar or slightly higher use of highest priority CIAs: in the UK, CIAs of highest priority accounted for just over $6 \%$ of AMs used in dogs and $34 \%$ in cats (calculated as number of events) (18) and in Australia $8 \%$ of the AM courses prescribed belonged to CIAs of highest priority, in which cats were 4.8-times more likely than dogs to receive 3 rd generation cephalosporins (21).

Second choice AMs (mainly aminopenicillins and 1st generation cephalosporins) represented the AMs most frequently used in studied Dutch companion animal clinics in 2012 and 2013. Aminopenicillins are categorized as CIAs with a high priority for human medicine (28). These findings are in line with studies in other countries $(18,21)$.

Total AMU in companion animals is decreasing and relatively low compared to livestock [e.g., in 2014 DDDA $_{\mathrm{NAT}}$ for cattle was 2.44, 21.15 for veal calves and 9.52 for pigs, respectively (29)] and AMU in humans [total AMU in the primary care sector of 10.58 DDD/1000 inhabitant days in 2014, corresponding to 3.86 $\mathrm{DDD} /$ inhabitant year (30)]. However, regarding the potential selection of ESBL-producing bacteria and regarding the use of 3rd choice AMs, there seems to be room for improvement in the classes and subclasses of AMs used in companion animals. Focus should be on further reduction of 2 nd and 3rd choice AMU.

Since January 2013, use of 3rd choice AMs as well as AMs authorized for human use is discouraged by legislation (susceptibility testing is mandatory). Therefore, the amount of 
AMs authorized for human use used in veterinary medicine is expected to be low. Based on the present study with veterinary wholesalers' procurement data, the exact amount of AMs authorized for human use (e.g., nitrofurantoin, some clindamycin, and trimethoprim/sulfonamide products) could not be calculated, because data from human pharmacies was not included.

Remarkable differences in AMU between clinics were observed. Overall AMU differed 20-fold in 2014, while for 3rd choice AMs this difference was 500-fold. The residual variance for 3rd choice AMU increased, indicating that differences between clinics with regard to 3rd choice AMU became more prominent. In human primary care the difference in number of antimicrobial courses between Dutch practices was only 5 -fold (31). Observed differences in present study might partially be attributed to differences in animal population between clinics. E.g., when clinics treat mainly small or very large breeds, the standardized average animal species weights used for DDDA calculations might not be correct and might cause under- or overestimation of the DDDACLINIC. Also differences in first opinion clinics vs. referral (i.e., secondary or tertiary) clinics, or clinics mainly treating emergency patients might account for observed differences between clinics. However and probably more important, AMU will be determined by prescribing policy and habits within companion animal clinics (e.g., the introduction and implementation of current guidelines regarding AMU) and veterinarian related prescribing habits, e.g., personal preferences in used dosages, frequency of dosing and course lengths as was shown in previous qualitative studies on AMU in companion animal clinics (32-34). The observation of clear and systematic differences between clinics in AMU highlights a potential for further optimization of AMU, eventually leading to smaller differences in AMU between clinics. Therefore, it is of interest to explore underlying factors which may explain differences in AMU between clinics in future studies more in-depth.

Only $8.7 \%$ of the 1,149 veterinary clinics treating companion animals were enrolled in present study. The representativeness of these clinics for all Dutch companion animal clinics might be questioned. Participating clinics might have had special interest in AMU and therefore display a more responsible attitude in their AMU compared to non-participating clinics. On the other hand, large differences in AMU between clinics could be observed, indicating that not only clinics with a low AMU were participating. Furthermore, participating clinics were distributed over the whole country. Therefore, the authors believe that the patterns of antimicrobial prescribing are likely to reflect those of the greater population and absolute DDDA numbers can be assumed to provide a reliable lower estimate of AMU across the remainder of the Dutch population of companion animal veterinary clinics.

In conclusion, systemic AMU in Dutch companion animal clinics is decreasing, in particular the use of $3 \mathrm{rd}$ choice AMs. However, substantial differences in AMU between clinics could be observed, both in (sub) classes as well as in total amount of AMs used, showing room for improvement.

\section{DATA AVAILABILITY}

The raw data supporting the conclusions of this manuscript will be made available by the authors, without undue reservation, to any qualified researcher.

\section{CONTRIBUTION TO THE FIELD}

AMR is recognized in human and in veterinary medicine as an increasing threat. The close contact between man and companion animals justifies the recognition of the importance of companion animals as potential reservoirs of (multi)-resistant pathogens for humans. AMR might have a direct impact on animal health and welfare as well. To prevent selection and spread of resistant bacteria and to keep AMs working and effective in the future, AMU should be optimized. In present study, a method was developed, using the number of DDDA, to quantify AMU. With this method used antimicrobial classes were explored and differences in prescribing patterns in time and between veterinary clinics were described. AMU was relatively low and decreasing in participating companion animal clinics, however substantial differences in prescribing practices between clinics suggest that there is still room for quantitative and qualitative improvement. The applied quantification method enables objectified comparison of AMU over time and between clinics, even internationally. Gathered data and developed quantification method will be used in future studies to explore AMU in Dutch companion animals more in-depth, to inform policy makers on AMU developments and to optimize AMU in companion animals.

\section{AUTHOR CONTRIBUTIONS}

$\mathrm{DH}, \mathrm{JW}, \mathrm{MvD}$, and IvG contributed to the concept and design of the study. MvD and IvG collected the data. $\mathrm{NH}$ and IvG performed the data analysis. All authors contributed to the writing and revising process of the manuscript.

\section{FUNDING}

This study has been conducted under contract with the SDa (The Netherlands Veterinary Medicines Institute) and was commissioned by the Ministry of Economic Affairs (Funding number 115704-1300019854 Survey antibioticumgebruik gezelschapsdieren).

\section{ACKNOWLEDGMENTS}

Preliminary results of the study were presented at the Annual Autumn Meeting of the Royal Dutch Veterinary Association, 2016, Utrecht, the Netherlands; Usage of antibiotics in companion animals from 2012 through 2014. We would like to express our gratitude to the participating veterinary clinics for providing their procurement and animal population data. We also would like to acknowledge the consultative group (Tjerk Bosje, Ed Hermens, Walter van Look, Saskia Nab, Louska Schipper, and Lonneke Stark) for enthusing veterinary clinics to 
participate and for critically reflecting on the data to be collected. Lastly, we would like to acknowledge Marleen Lenssinck, Femke Taverne, Sanne van Beers, Janneke van Velthuizen, Peter Essers, and Joep Bolwerk for their help during data collection and Lützen Portengen and Pim Sanders for their support in using SAS during data analysis.

\section{REFERENCES}

1. Guardabassi L, Schwarz S, Lloyd DH. Pet animals as reservoirs of antimicrobial-resistant bacteria. J Antimicrob Chemother. (2004) 54:321-32. doi: $10.1093 / \mathrm{jac} / \mathrm{dkh} 332$

2. Lloyd DH. Reservoirs of antimicrobial resistance in pet animals. Clin Infect Dis. (2007) 45 (Suppl. 2):S148-S152. doi: 10.1086/519254

3. Chomel B, Sun B. Zoonoses in the bedroom. Emerging Infect Dis. (2011) 17:167-72. doi: 10.3201/eid1702.101070

4. Hordijk J, Schoormans A, Kwakernaak M, Duim B, Broens E, Dierikx C, et al. High prevalence of fecal carriage of extended spectrum beta-lactamase/AmpC-producing enterobacteriaceae in cats and dogs. Front Microbiol. (2013) 4:242. doi: 10.3389/fmicb.2013. 00242

5. Pomba C, Rantala M, Greko C, Baptiste KE, Catry B, van Duijkeren E, et al. Public health risk of antimicrobial resistance transfer from companion animals. J Antimicrob Chemother. (2017) 72:957-68. doi: 10.1093/jac/ dkw481

6. LETTER TO THE PARLIAMENT. Convenant Antibioticaresistentie Dierhouderij, 08-12-2008. (2008).

7. NETHMAP/MARAN. NethMap: Consumption of Antimicrobial Agents and Antimicrobial Resistance Among Medically Important Bacteria in the Netherlands/MARAN: Monitoring of Antimicrobial Resistance and Antibiotic Usage in Animals in the Netherlands in 2016. (2017).

8. Speksnijder DC, Mevius DJ, Bruschke CJ, Wagenaar JA. Reduction of veterinary antimicrobial use in the Netherlands. The Dutch success model. Zoonoses Public Health. (2015) 62 (Suppl. 1):79-87. doi: 10.1111/zph. 12167

9. SDa (the Netherlands Veterinary Medicines Institute). Usage of Antibiotics in Agricultural Livestock in the Netherlands in 2017. (2018).

10. STAATSCOURANT. Regeling van de Staatssecretaris van Economische Zaken van 14 Januari 2013, nr. WJZ / 13002270, Houdende Wijziging van de Regeling Diergeneesmiddelen in Verband met het Uitvoeren van een Gevoeligheidsbepaling bij Toepassing of Aflevering van Bepaalde Diergeneesmiddelen. (2013).

11. Grave K, Jensen VF, Odensvik K, Wierup M, Bangen M. Usage of veterinary therapeutic antimicrobials in Denmark, Norway and Sweden following termination of antimicrobial growth promoter use. Prev Vet Med. (2006) 75:123-32. doi: 10.1016/j.prevetmed.2006. 02.003

12. Jensen VF, Emborg HD, Aarestrup FM. Indications and patterns of therapeutic use of antimicrobial agents in the Danish pig production from 2002 to 2008. J Vet Pharmacol Ther. (2012) 35:33-46. doi: 10.1111/j.1365-2885.2011.01291.x

13. Bos ME, Taverne FJ, van Geijlswijk IM, Mouton JW, Mevius DJ, Heederik DJ, et al. Consumption of antimicrobials in pigs, veal calves, and broilers in the Netherlands: quantitative results of nationwide collection of data in 2011. PLoS ONE. (2013) 8:e77525. doi: 10.1371/journal.pone.00 77525

14. De Briyne N, Atkinson J, Pokludova L, Borriello SP. Antibiotics used most commonly to treat animals in Europe. Vet Rec. (2014) 175:325. doi: $10.1136 /$ vr. 102462

15. Grave K, Torren-Edo J, Muller A, Greko C, Moulin G, Mackay D, et al. Variations in the sales and sales patterns of veterinary antimicrobial agents in 25 European countries. J Antimicrob Chemother. (2014) 69:2284-91. doi: $10.1093 / \mathrm{jac} / \mathrm{dku} 106$

16. Obritzhauser W, Trauffler M, Raith J, Kopacka I, Fuchs K, Kofer J. Antimicrobial drug use on Austrian dairy farms with special consideration of the use of "highest priority critically important antimicrobials". Berl Munch Tierarztl Wochenschr. (2016) 129:185-95. doi: 10.2376/0005-9366-129-15035
17. Escher M, Vanni M, Intorre L, Caprioli A, Tognetti R, Scavia G. Use of antimicrobials in companion animal practice: a retrospective study in a veterinary teaching hospital in Italy. J Antimicrob Chemother. (2011) 66:9207. doi: $10.1093 / \mathrm{jac} / \mathrm{dkq} 543$

18. Buckland EL, O'Neill D, Summers J, Mateus A, Church D, Redmond L, et al. Characterisation of antimicrobial usage in cats and dogs attending UK primary care companion animal veterinary practices. Vet Rec. (2016) 179:489. doi: $10.1136 /$ vr. 103830

19. Hardefeldt LY, Browning GF, Thursky K, Gilkerson JR, BillmanJacobe $\mathrm{H}$, Stevenson MA, et al. Antimicrobials used for surgical prophylaxis by companion animal veterinarians in Australia. Vet Microbiol. (2017) 203:301-7. doi: 10.1016/j.vetmic.2017. 03.027

20. Singleton DA, Sanchez-Vizcaino F, Dawson S, Jones PH, Noble PJM, Pinchbeck GL, et al. Patterns of antimicrobial agent prescription in a sentinel population of canine and feline veterinary practices in the United Kingdom. Vet J. (2017) 224:18-24. doi: 10.1016/j.tvjl.2017. 03.010

21. Hardefeldt LY, Selinger J, Stevenson MA, Gilkerson JR, Crabb H, BillmanJacobe $\mathrm{H}$, et al. Population wide assessment of antimicrobial use in dogs and cats using a novel data source - a cohort study using pet insurance data. Vet Microbiol. (2018) 225:34-9. doi: 10.1016/j.vetmic.2018. 09.010

22. Hardefeldt LY, Holloway S, Trott DJ, Shipstone M, Barrs VR, Malik R, et al. Antimicrobial prescribing in dogs and cats in Australia: results of the Australasian infectious disease advisory panel survey. J Vet Intern Med. (2017) 31:1100-7. doi: 10.1111/jvim. 14733

23. EMA. Principles on Assignment of Defined Daily Dose for Animals (DDDvet) and Defined Course Dose for Animals (DCDvet). EMA/710019/2014. (2015).

24. EMA. Defined Daily Doses for Animals (DDDvet) and Defined Course Doses for Animals (DCDvet). European Surveillance of Veterinary Antimicrobial Consumption (ESVAC). EMA/224954/ 2016. (2016).

25. EMA. Overview of Comments Received on 'Guidance on Collection and Provision of National Data on Antimicrobial Use by Animal Species/Categories' (EMA/489035/2016). EMA/619729/2017. (2018).

26. Van Geijlswijk I, Alsters S, Schipper L. Prescription of antimicrobial agents in companion animal practices. Tijdschr Diergeneeskd. (2013) 138:26-9.

27. HAS University of Applied Sciences, HAS Training and Consultancy, Den Bosch and Faculty of Veterinary Medicine, Utrecht. Feiten and Cijfers Gezelschapsdieren 2015. (2015). Available online at: https:// www.rijksoverheid.nl/documenten/rapporten/2015/11/03/feiten-cijfersgezelschapsdierensector-2015 (accessed February 22, 2019)

28. WHO. Critically Important Antimicrobials for Human Medicine. 5th Revision. (2017).

29. NETHMAP/MARAN. NethMap: Consumption of Antimicrobial Agents and Antimicrobial Resistance Among Medically Important Bacteria in the Netherlands/MARAN: Monitoring of Antimicrobial Resistance and Antibiotic Usage in Animals in the Netherlands in 2014. (2015).

30. ECDC. Country Overview of Antimicrobial Consumption: Antimicrobial Consumption in the Netherlands. (2014). Available online at: https:// ecdc.europa.eu/en/antimicrobial-consumption/database/country-overview (accessed February 22, 2019)

31. Van der Velden AW, Kuyvenhoven MM, Verheij TJ. Improving antibiotic prescribing quality by an intervention embedded in the primary care practice accreditation: the ARTI4 randomized trial. J Antimicrob Chemother. (2016) 71:257-63. doi: 10.1093/jac/dkv328

32. Mateus AL, Brodbelt DC, Barber N, Stark KD. Qualitative study of factors associated with antimicrobial usage in seven small animal 
veterinary practices in the UK. Prev Vet Med. (2014) 117:68-78. doi: 10.1016/j.prevetmed.2014.05.007

33. Hopman NEM, Hulscher MEJL, Graveland H, Speksnijder DC, Wagenaar JA, Broens EM. Factors influencing antimicrobial prescribing by Dutch companion animal veterinarians: a qualitative study. Prev Vet Med. (2018) 158:106-13. doi: 10.1016/j.prevetmed.2018. 07.013

34. King C, Smith M, Currie K, Dickson A, Smith F, Davis M, et al. Exploring the behavioural drivers of veterinary surgeon antibiotic prescribing: a qualitative study of companion animal veterinary surgeons in the UK. BMC Vet. Res. (2018) 14:332. doi: 10.1186/s12917-018-1646-2
Conflict of Interest Statement: The authors declare that the research was conducted in the absence of any commercial or financial relationships that could be construed as a potential conflict of interest.

Copyright (c) 2019 Hopman, van Dijk, Broens, Wagenaar, Heederik and van Geijlswijk. This is an open-access article distributed under the terms of the Creative Commons Attribution License (CC BY). The use, distribution or reproduction in other forums is permitted, provided the original author(s) and the copyright owner(s) are credited and that the original publication in this journal is cited, in accordance with accepted academic practice. No use, distribution or reproduction is permitted which does not comply with these terms. 